\title{
Effects of modular ion-funnel technology onto analysis of breath VOCs by means of real-time mass spectrometry
}

\author{
Giovanni Pugliese $^{1} \cdot$ Felix Piel $^{2,3,4} \cdot$ Phillip Trefz $^{1} \cdot$ Philipp Sulzer $^{2} \cdot$ Jochen K. Schubert $^{1} \cdot$ Wolfram Miekisch $^{1}$
}

Received: 27 March 2020 / Revised: 21 July 2020 / Accepted: 24 July 2020 / Published online: 13 August 2020

(C) The Author(s) 2020

\begin{abstract}
Proton transfer reaction time-of-flight mass spectrometry (PTR-ToF-MS) is a powerful tool for real-time monitoring of trace concentrations of volatile organic compounds (VOCs). The sensitivity of PTR-ToF-MS also depends on the ability to effectively focus and transmit ions from the relatively high-pressure drift tube (DT) to the low-pressure mass analyzer. In the present study, a modular ion-funnel (IF) is placed adjacent to the DT of a PTR-ToF-MS instrument to improve the ion-focusing. IF consists of a series of electrodes with gradually decreasing orifice diameters. Radio frequency (RF) voltage and direct current (DC) electric field are then applied to the electrodes to get the ions focused. We investigated the effect of the RF voltage and DC field on the sensitivity of a pattern of VOCs including hydrocarbons, alcohols, aldehydes, ketones, and aromatic compounds. In a proof-ofconcept study, the instrument operating both as normal DT (DC-mode) and at optimal IF conditions (RF-mode) was applied for the breath analysis of 21 healthy human subjects. For the range of investigated VOCs, an improvement of one order of magnitude in sensitivity was observed in RF-mode compared with DC-mode. Limits of detection could be improved by a factor of 2-4 in RF-mode compared with DC-mode. Operating the instrument in RF-mode allowed the detection of more compounds in the exhaled air compared with DC-mode. Incorporation of the IF considerably improved the performance of PTR-ToF-MS allowing the real-time monitoring of a larger number of potential breath biomarkers.
\end{abstract}

Keywords PTR-ToF-MS $\cdot$ Ion-funnel $\cdot$ Real-time mass spectrometry $\cdot$ Breath analysis $\cdot$ VOCs

\section{Introduction}

Proton transfer reaction mass spectrometry (PTR-MS) is an analytical technique that allows real-time monitoring of volatile organic compounds (VOCs) at low concentrations. It is

Electronic supplementary material The online version of this article (https://doi.org/10.1007/s00216-020-02846-8) contains supplementary material, which is available to authorized users.

Wolfram Miekisch

wolfram.miekisch@uni-rostock.de

1 Department of Anaesthesia and Intensive Care, Rostock University Medical Center, Schillingallee 35, 18057 Rostock, Germany

2 IONICON Analytik GmbH, Eduard-Bodem-Gasse 3, 6020 Innsbruck, Austria

3 Institute for Ion Physics and Applied Physics, University of Innsbruck, Technikerstr. 25, 6020 Innsbruck, Austria

4 Present address: Department of Chemistry, University of Oslo, Sem Sælands vei 26, 0371 Oslo, Norway widely used, e.g. in environmental sciences, food chemistry, homeland security, and breath analysis [1].

Since its introduction in the 1990s [2], PTR-MS has been improved in many ways. Inclusion of time-of-flight (ToF) mass analyzers has substantially overcome the limitations of the first generation of PTR quadrupole-MS (QMS) such as limited mass range and low mass resolution [3-5]. Modifications of the hollow cathode discharge ion source allowed to successfully use different chemical ionization agents such as $\mathrm{H}_{3} \mathrm{O}^{+}, \mathrm{NO}^{+}, \mathrm{O}_{2}{ }^{+}, \mathrm{Kr}^{+}, \mathrm{Xe}^{+}$, and $\mathrm{NH}_{4}{ }^{+}$, improving versatility and selectivity of the instrument $[6,7]$.

Sensitivity of PTR-MS is not solely determined by mass analyzers and detectors but it also depends on the ability to effectively focus and transmit ions from the relatively highpressure drift tube (DT) to the low-pressure mass analyzer. As most of the ions crossing the DT do not exit through the small orifice at the MS interface, a large quantity of ion signal is lost. Ion-funnels (IF) represent a kind of ion guide that enhances sampling of ions through an orifice [8]. In an IF, a radio frequency (RF) voltage and a direct current (DC) electric field are applied to a series of electrodes with decreasing aperture 
sizes. The electrodes provide strong repulsive potentials at the edge of the electrode, radially focusing the ions. The first demonstration of an IF in PTR-MS was shown by Barber et al. [9]. In their instrument, the whole DT was set up as an IF with the first half used as a standard DT reactor running at a lower reduced electric field compared with the traditional DT. The RF electric field was only applied to the second section with decreasing orifice sizes. González-Méndez et al. [10] used the IF to manipulate the ion-molecule reactions and enhance the selectivity of PTR-MS. Brown et al. [11] reported that in this instrument, ion-focusing and proton transfer reaction both occurred in the IF region. This resulted in vastly different sensitivities for different compounds and in unusual fragmentation patterns. Recently, IONICON Analytik implemented a modular IF into proton transfer reaction time-offlight mass spectrometry (PTR-ToF-MS) instruments. The aim of the present study was to characterize and optimize the IF-PTR-ToF instrument for trace VOC analysis. In a proof-of-concept setup, the instrument was then applied for real-time breath analysis in human subjects. The following questions were addressed in detail:

- How does modification of IF parameters affect primary and VOC product ions?

- Are PTR sensitivity and detection limits in VOC analysis significantly improved by the IF?

- Are benefits of the IF technique suited to support applications such as real-time breath gas analysis in humans?

\section{Methods}

\section{Ion-funnel PTR-ToF-MS instrument}

All investigations were carried out using an online PTR-ToFMS instrument equipped with a modular IF (PTR-TOF 1000 ultra, IONICON Analytik GmbH, Innsbruck, Austria; firstgeneration model (2017)). Figure 1 shows a schematic view of the instrument. The general working principle of PTR-ToFMS has been described in several studies $[4,5]$. Concisely, hydronium ions $\left(\mathrm{H}_{3} \mathrm{O}^{+}\right)$are produced in a hollow cathode glow discharge ion source from electron ionization of water vapour and are drawn by an electric field into the ion-molecule reaction region (DT). Here, the analyte sample is injected and the proton transfer reaction between the formed $\mathrm{H}_{3} \mathrm{O}^{+}$and neutral analyte molecules (M) occurs: $\mathrm{M}+\mathrm{H}_{3} \mathrm{O}^{+} \rightarrow \mathrm{MH}^{+}+$ $\mathrm{H}_{2} \mathrm{O}$. Only molecules with proton affinities higher than water $\left(\mathrm{PA}\left(\mathrm{H}_{2} \mathrm{O}\right)=691 \mathrm{~kJ} \mathrm{~mol}^{-1}\right)$ are ionized, a criterion that excludes the major constituents of air such as $\mathrm{N}_{2}, \mathrm{O}_{2}$, and $\mathrm{CO}_{2}$ but includes many trace gases such as most VOCs. The DT of the PTR-TOF 1000 ultra consists of a $7 \mathrm{~cm}$ long tube made of electrically isolated stainless steel rings. The rings are

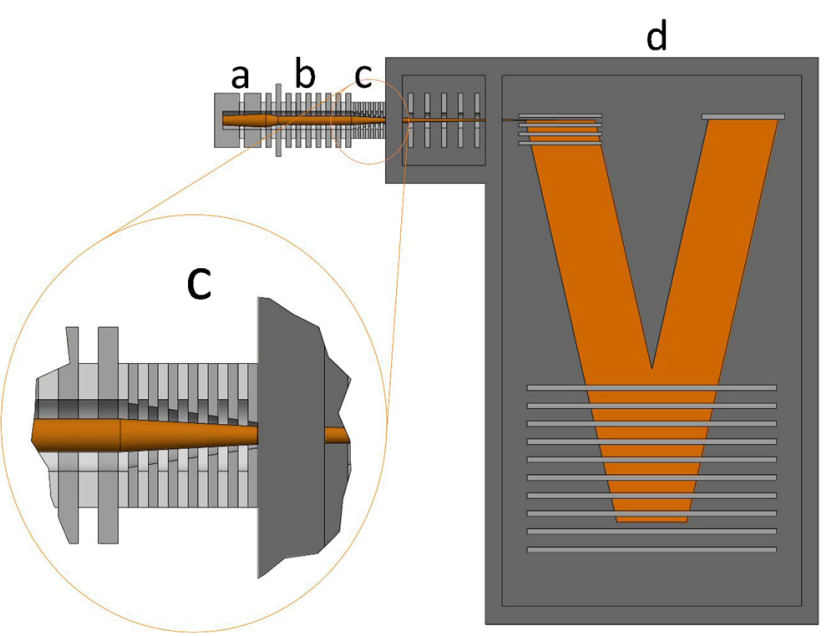

Fig. 1 Schematic view of the PTR-ToF 1000 ultra setup: (a) hollow cathode ion source, (b) drift tube, (c) ion-funnel, (d) ToF mass analyzer

connected with resistors, and a drift voltage $\left(U_{\text {drift }}\right)$ can be applied over the entire set of rings to induce an electric field $\left(E_{\text {drift }}\right)$ in the DT. The modular IF is $2.2 \mathrm{~cm}$ long, it is placed adjacent to the DT and consists of 12 electrodes (6 with RF+ and 6 with $\mathrm{RF}-$ ) with gradually decreasing orifice diameters, from 1 to $0.2 \mathrm{~cm}$, placed at $0.1 \mathrm{~cm}$ distance of each other. In order to avoid the trapping of ions in axial potential wells, particularly those with low $\mathrm{m} / \mathrm{z}$, the IF electrode geometries used in this work fulfilled the following conditions:

$2 \pi \frac{\rho}{\delta} \exp \left(\frac{-2 \rho}{\delta}\right) \ll 1$

where $\rho$ is the electrode orifice radius and $\delta=d / \pi$ where $d$ is the electrode spacing [12]. A radio frequency (RF) voltage and a direct current (DC) electric field are then applied to the electrodes. The DC electric field drives the ions axially through the IF toward the exit aperture. An additional alternating current (AC) is superimposed on the electrodes, with the RF on neighbouring electrodes being phase-shifted by $180^{\circ}$. In this way, the RF field creates a strongly repulsive potential near the surface of each electrode. In combination with the progressively decreasing aperture size, this serves to focus the ions radially. Table S1 (see Electronic Supplementary Material, ESM) summarizes details and operating conditions of the modular IF. The protonated VOCs then enter the pulse extraction region of the orthogonal acceleration reflectron ToF analyzer via a transfer lens system. The DT is interfaced to the transfer lens region via a pinhole of $\sim 0.1 \mathrm{~cm}$ I.D. with the cone toward the transfer lens. The operating pressure in the DT (buffer gas number density, $N$ ) and the $E_{\text {drift }}$ strength are important parameters, more commonly combined and expressed in terms of the reduced electric field ( $E /$ $N) . E_{\text {drift }}$ accelerates the ions but at the same time collisions with the buffer gas tend to slow them down. The $E / N$ affects the reagent ion distribution. Increasing the $E / N$ ratio results in 
more energetic collisions, which reduces the proportion of the water cluster ions $\left(\mathrm{H}_{3} \mathrm{O}^{+}\left(\mathrm{H}_{2} \mathrm{O}\right)_{n}\right)$ in the DT but at the same time can increase the fragmentation of analytes [13]. Typical $E / N$ values are in the range $90-150 \mathrm{Td}$, where $1 \mathrm{Td}=$ $10^{-17} \mathrm{~V} \mathrm{~cm}^{2}$.

Within the standard PTR DT, $E_{\text {drift }}$ variation is about $15 \%$ due to the ratio of the inner diameter and axial distance between the drift rings [14]. The additional RF voltage considerably increases this variation and $E / N$ cannot be properly calculated any more. However, it is possible to define certain voltage settings in RF-mode which enable branching ratios of distinct analytes to be obtained that are comparable with the ones obtained with a classic PTR-ToF-MS instrument operated at a certain actual $E / N$ (“TRU- $E / N$ " method). Nevertheless, in the present paper, the $E / N$ definition is omitted.

\section{Ion-funnel characterization}

\section{Gas standard generation}

The IF characterization was performed using a multicomponent gas VOC mix (IONICON Analytik GmbH, Innsbruck, Austria) including methanol, acetonitrile, acetaldehyde, ethanol, 2-propenal, acetone, isoprene, 2butenal, 2-butanone, benzene, toluene, $o$-xylene, chlorobenzene, $\alpha$-pinene, and 1,2-dichlorobenzene at concentrations of $\sim 1 \mathrm{ppmV}$. The VOC mix was subjected to a 100-fold dynamic dilution in pure nitrogen (purity 5.0, Linde, Vienna, Austria) by means of a liquid calibration unit (LCU, IONICON Analytik, Innsbruck, Austria) to generate a standard mixture with approximately $10 \mathrm{ppbV}$ of each component. The working principle of the LCU involves the introduction of a liquid standard solution into a carrier gas stream, by forcing it through a nebuliser (X175, Burgener Research Inc., UK) and spraying the solution into an evaporation chamber at a defined temperature. This results in a rapid evaporation. The generated gaseous standard mixture can then be measured or collected directly at the output of the evaporation chamber. Two liquid ports $\left(1-50 \mu 1 \mathrm{~min}^{-1}\right)$, one carrier gas port (1-1000 $\left.\mathrm{ml} \mathrm{min}^{-1}\right)$, and two additional

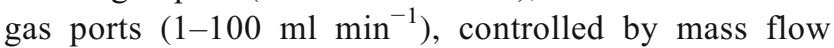
controllers (Bronkhorst High-Tech B.V., Ruurlo, Netherlands), enable the generation of complex standard mixtures. VOC standards can be prepared from either liquid solutions or gases, or even from both at the same time. In addition, defined amounts of humidity can be added by adding pure water via one of the two liquid ports [15].

In this study, the LCU flow was kept constant at

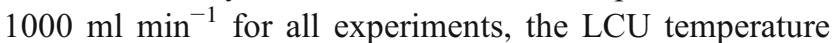
was $75{ }^{\circ} \mathrm{C}$ and the humidity was adjusted by adding pure water (HPLC grade).

\section{Experimental design}

The standard mixture was introduced into the DT via a $1.5 \mathrm{~m}$ long polyether ether ketone (PEEK) transfer line (ID: $0.75 \mathrm{~mm}$, Restek, Bellafonte, PA) that was directly connected to the outlet of the LCU. The transfer line temperature was $75{ }^{\circ} \mathrm{C}$ and the sampling flow was $100 \mathrm{ml} \mathrm{min}^{-1}$. The signal intensity was recorded for each $\mathrm{m} / \mathrm{z}$ while the settings of the IF region were varied. Operating the instrument in RF-mode (RF on), the DC electric field applied to the IF was varied in the range of 4.5$27 \mathrm{~V} / \mathrm{cm}$ while the RF voltage was varied in the range of 40 $200 \mathrm{~V}$ peak-to-peak $\left(\mathrm{V}_{\mathrm{p}-\mathrm{p}}\right)$ at $4.5 \mathrm{MHz}$. These testing ranges were decided upon after preliminary measurements showed that these settings approximate the best operating conditions. The entire experimental design was repeated at two different $E_{\text {drift }}$ strength, $66 \mathrm{~V} / \mathrm{cm}$ and $48 \mathrm{~V} / \mathrm{cm}$, and using both dry and humid samples (absolute humidity $47 \mathrm{~g} \mathrm{~m}^{-3}$ ) (ESM Table S2). These two sampling conditions will be referred in the text as "dry" and "humid" conditions, respectively.

When the instrument was operated only with the DC field applied to the IF region (DC-mode), the RF voltage was set to zero and the DC field was set at the same $E_{\text {drift }}$ value in order to have a homogeneous electric field along the DT/IF regions.

For the whole experimental design, the DT/IF pressure was 2.3 mbar, the DT temperature was $75^{\circ} \mathrm{C}$, and the integration time was $1 \mathrm{~s}$.

Three replicates were measured for each experimental setup, then the results were averaged and background signals were subtracted.

\section{Human breath samples}

All experiments were performed in accordance with the guidelines laid down in the Declaration of Helsinki and approved by the ethics committee at the University Medical Center Rostock. Informed consent was obtained from 21 healthy human subjects (aged between 20 and 45 years). Demographic parameters such as height, body weight, age, sex, and smoking habits were recorded for each volunteer (ESM Table S3). Volunteers were asked to breathe spontaneously and continuously over $3 \mathrm{~min}$ through a sterile mouth piece directly connected to the PTR transfer line in side stream mode by means of a T-piece. During the first minute of measurement, the PTR-ToF-MS instrument was operated in RF mode: $E_{\text {drift }}$ was $66 \mathrm{~V} / \mathrm{cm}$, RF voltage was $120 \mathrm{~V}_{\mathrm{p}-\mathrm{p}}$, and DC field was $13.5 \mathrm{~V} / \mathrm{cm}$. During the second minute of measurement, the operating mode of the instrument was switched from RF-mode to DC-mode. During the third minute of measurement, the instrument was operated in DC-mode: RF voltage was $0 \mathrm{~V}_{\mathrm{p}-\mathrm{p}}$ and both $E_{\text {drift }}$ and DC field were $66 \mathrm{~V} / \mathrm{cm}$.

For breath measurements, the PTR transfer line temperature was $75^{\circ} \mathrm{C}$, DT temperature was $75^{\circ} \mathrm{C}$, and DT pressure was 2.3 mbar. For breath measurements, the integration time was $200 \mathrm{~ms}$. 


\section{Data processing}

The ion yields of all $\mathrm{m} / \mathrm{z}$ were measured in counts per second (cps) and compounds were identified by means of their protonated $\mathrm{m} / \mathrm{z}$ and isotopic patterns. The normalization of the measured ion intensities to the $\mathrm{H}_{3} \mathrm{O}^{+}$counts in combination with the water-cluster ion counts is standard practice in PTRToF-MS data treatment [16]. However, in the present paper, the normalization to reagent ions was omitted in order to reflect the actual sensitivity of the instrument, which would be masked by normalization.

Both breath and standard files were processed using the software PTR-MS viewer v. 3.2.8 (IONICON Analytik GmbH, Innsbruck, Austria).

For breath measurements, expiratory and inspiratory phases were recognized by means of a custom-made data processing algorithm called "breath tracker" (MATLAB version 7.12.0.635, R2011a). The function of the algorithm has been described previously [17]. Briefly, an endogenous compound that has a sufficiently abundant signal intensity in expiration is used as a tracker to differentiate between alveolar and inspired phases. Acetone, isoprene, or carbon dioxide is usually used for this purpose. Expiratory and inspiratory phases determined by means of the algorithm were then applied to all $\mathrm{m} / \mathrm{z}$ of interest.

\section{Results}

\section{Ion-funnel characterization}

\section{$\mathrm{H}_{3} \mathrm{O}^{+} \cdot\left(\mathrm{H}_{2} \mathrm{O}\right)_{n}(n=0,1$, and 2$)$ reagent ions}

Figure $2(\mathrm{a}, \mathrm{b})$ shows the variation of $\mathrm{H}_{3} \mathrm{O}^{+}$, protonated water clusters, and $\mathrm{O}_{2}{ }^{+}$and $\mathrm{NO}^{+}$measured intensities as function of RF voltage. The signal intensities of $\mathrm{H}_{3} \mathrm{O}^{+}, \mathrm{H}_{2} \mathrm{O} \cdot \mathrm{H}_{3} \mathrm{O}^{+}$, and $\mathrm{O}_{2}{ }^{+}$are too high to be measured directly because of detector saturation. Therefore, the signal intensities at $m / z=21$ corresponding to $\mathrm{H}_{3}{ }^{18} \mathrm{O}^{+}$, at $m / z=39$ corresponding to $\mathrm{H}_{2} \mathrm{O}$. $\mathrm{H}_{3}{ }^{18} \mathrm{O}^{+}$and at $\mathrm{m} / \mathrm{z}=34$ corresponding to ${ }^{18} \mathrm{O}^{16} \mathrm{O}^{+}$were recorded and corrected by the natural isotope abundances.

$\mathrm{H}_{3} \mathrm{O}^{+}$intensity showed its maximum value at $\mathrm{RF}=80 \mathrm{~V}$-p under dry conditions (Fig. 2 (a)) and at RF $=120 \mathrm{~V}$ under humid conditions (Fig. 2 (b)). As the RF voltage decreases, the $\mathrm{H}_{3} \mathrm{O}^{+}$signal intensity decreases. At the same time, an increase of the water cluster intensities was observed with decreasing RF voltage. $\mathrm{H}_{3} \mathrm{O}^{+} \cdot \mathrm{H}_{2} \mathrm{O}$ showed its maximum value at $R F=40 V_{p-p}$ under dry conditions and at $R F=80 V_{p-p}$ under humid conditions. Nevertheless, at $R F=40 \mathrm{~V}_{\mathrm{p}-\mathrm{p}}$ under humid conditions, $\mathrm{H}_{3} \mathrm{O}^{+} \cdot \mathrm{H}_{2} \mathrm{O}$ showed a higher intensity than $\mathrm{H}_{3} \mathrm{O}^{+}$.

The protonated water trimer was only observed under humid conditions and at $\mathrm{RF}=40 \mathrm{~V}_{\mathrm{p}-\mathrm{p}}$. Intensities of parasitic
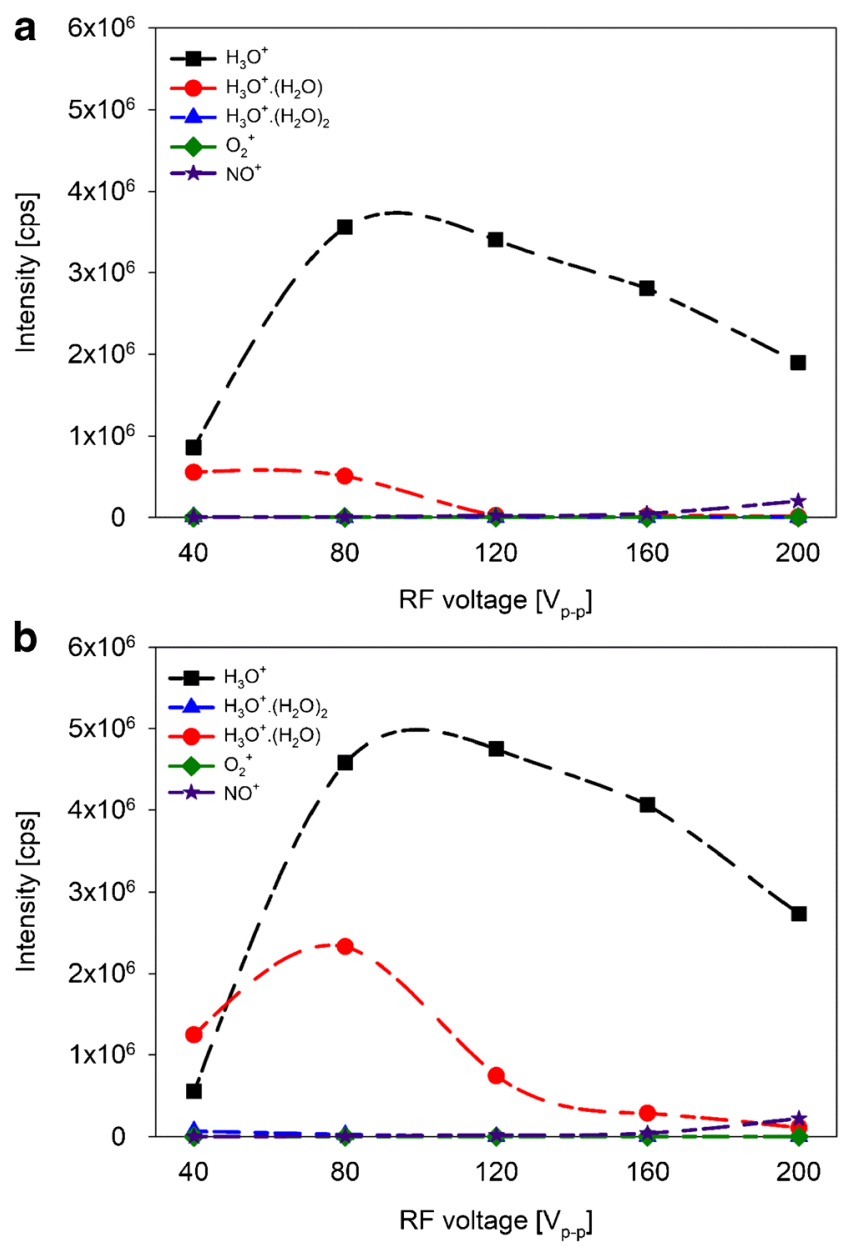

Fig. 2 Ion intensities in counts per second (cps) of the water reagent ions $\left(\mathrm{H}_{3} \mathrm{O}^{+} \cdot\left(\mathrm{H}_{2} \mathrm{O}\right)_{n}, n=0,1\right.$, and 2$)$ and parasitic ions $\mathrm{O}_{2}{ }^{+}$and $\mathrm{NO}^{+}$present in the DT under dry (a) and humid (b) conditions as a function of RF voltage. DC was $13.5 \mathrm{~V} / \mathrm{cm}$ and $E_{\text {drift }}$ was $66 \mathrm{~V} / \mathrm{cm}$

ions $\mathrm{O}_{2}{ }^{+}$and $\mathrm{NO}^{+}$only increased only at high $\mathrm{RF}$ voltages $\left(>160 \mathrm{~V}_{\mathrm{p}-\mathrm{p}}\right)$ under both dry and humid conditions. $\mathrm{H}_{3} \mathrm{O}^{+}$. $\left(\mathrm{H}_{2} \mathrm{O}\right)_{2}$ and $\mathrm{O}_{2}{ }^{+}$intensities were up to six orders of magnitude smaller compared with that of the protonated water dimer.

Figure $3(a, b)$ shows the variation of the $\mathrm{H}_{3} \mathrm{O}^{+}$and $\mathrm{H}_{3} \mathrm{O}^{+}$. $\mathrm{H}_{2} \mathrm{O}$ intensities as function of DC field. Due to the large difference between the intensities of the two reagent ions, $\mathrm{H}_{3} \mathrm{O}^{+}$. $\mathrm{H}_{2} \mathrm{O}$ intensity is displayed on a second $Y$-axis. The $\mathrm{H}_{3} \mathrm{O}^{+}$ intensity increased with increasing DC field with its maximum value at $\mathrm{DC}=27 \mathrm{~V} / \mathrm{cm}$ under both dry (Fig. 3 (a)) and humid (Fig. 3 (b)) conditions. In contrast, $\mathrm{H}_{3} \mathrm{O}^{+} \cdot \mathrm{H}_{2} \mathrm{O}$ showed its maximum value at $\mathrm{DC}=22.5 \mathrm{~V} / \mathrm{cm}$ under both dry and humid conditions.

ESM Fig. $\mathrm{S} 1(\mathrm{a}, \mathrm{b})$ shows the variation of $\mathrm{H}_{3} \mathrm{O}^{+}$, protonated water clusters, and $\mathrm{O}_{2}{ }^{+}$and $\mathrm{NO}^{+}$measured intensities as function of RF voltage at $E_{\text {drift }}=48 \mathrm{~V} / \mathrm{cm}$. ESM Fig. S2 (a, b) shows the variation of the $\mathrm{H}_{3} \mathrm{O}^{+}$and $\mathrm{H}_{3} \mathrm{O}^{+} \cdot \mathrm{H}_{2} \mathrm{O}$ intensities as function of DC voltage at $E_{\text {drift }}=48 \mathrm{~V} / \mathrm{cm} . \mathrm{H}_{3} \mathrm{O}^{+}$intensity showed similar trends of those showed at $E_{\text {drift }}=66 \mathrm{~V} / \mathrm{cm}$. In contrast, substantial differences were found for the protonated 
Fig. 3 Ion intensities in counts per second (cps) of $\mathrm{H}_{3} \mathrm{O}^{+}$and $\mathrm{H}_{3} \mathrm{O}^{+} \cdot\left(\mathrm{H}_{2} \mathrm{O}\right)$ present in the DT under dry (a) and humid (b) conditions as a function of the DC field $(\mathrm{V} / \mathrm{cm})$. RF voltage was $120 \mathrm{~V}_{\mathrm{p}-\mathrm{p}}$ and $E_{\text {drift }}$ was $66 \mathrm{~V} / \mathrm{cm}$
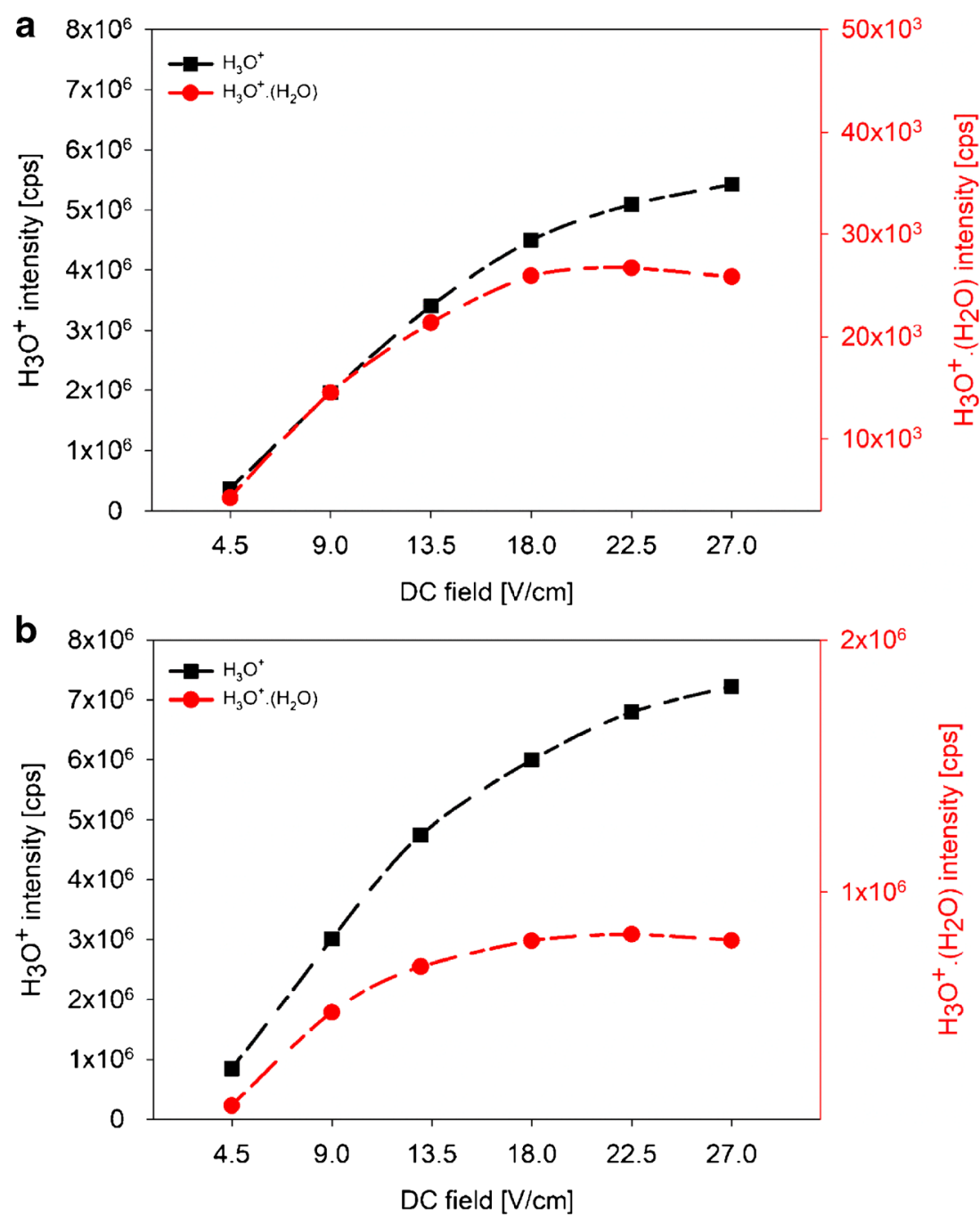

water clusters. Under dry conditions (ESM Fig. S1 (a)) at $\mathrm{RF}=40 \mathrm{~V}_{\mathrm{p}-\mathrm{p}}$ and under humid conditions (ESM Fig. S1 (b)) at $\mathrm{RF}=80 \mathrm{~V}_{\mathrm{p}-\mathrm{p}}, \mathrm{H}_{3} \mathrm{O}^{+} \cdot \mathrm{H}_{2} \mathrm{O}$ became the most abundant reagent ion in the DT. Under humid conditions at $\mathrm{RF}=40 \mathrm{~V}_{\mathrm{p}}$ p, $\mathrm{H}_{3} \mathrm{O}^{+} \cdot\left(\mathrm{H}_{2} \mathrm{O}\right)_{2}$ showed a higher intensity than $\mathrm{H}_{3} \mathrm{O}^{+}$.

In DC-mode at $E_{\text {drift }}=48 \mathrm{~V} / \mathrm{cm}$ under humid conditions, $\mathrm{H}_{3} \mathrm{O}^{+} \cdot \mathrm{H}_{2} \mathrm{O}$ represent about $65 \%$ of the total water reagent ions. In contrast, under dry conditions, they represent about the $15 \%$ of the total water reagent ions. In DC-mode at $E_{\text {drift }}=$ $66 \mathrm{~V} / \mathrm{cm}$, protonated water clusters are present in low concentrations under both dry and humid conditions. Under humid conditions, $\mathrm{H}_{3} \mathrm{O}^{+} \cdot \mathrm{H}_{2} \mathrm{O}$ represent about $8 \%$ of the total water reagent ions; under dry conditions, they represent about $1 \%$ of the total water reagent ions.

\section{Effect of RF voltage and DC field on VOC signal intensities}

Figure 4 shows effects of RF voltage (40-200 $\left.\mathrm{V}_{\mathrm{p}-\mathrm{p}}\right)$ and DC field $(4.5-27 \mathrm{~V} / \mathrm{cm})$ onto intensities of all investigated VOCs.
Figure 5 shows signal intensities of acetaldehyde, acetone, benzene, and dichlorobenzene as a function of RF voltage.

Intensities of acetaldehyde, methanol, ethanol, 2propenal, and isoprene showed their maximum values at $\mathrm{RF}=80 \mathrm{~V}_{\mathrm{p}-\mathrm{p}}$. In contrast, intensities of acetone, acetonitrile, 2-butenal, and butanone showed their maximum values at $\mathrm{RF}=120 \mathrm{~V}_{\mathrm{p}-\mathrm{p}}$. Aromatic compounds, such as benzene, toluene, $o$-xylene, chlorobenzene, and $\alpha$-pinene, showed their maximum intensities at $R F=160 \mathrm{~V}_{\mathrm{p}-\mathrm{p}}$. Intensity of dichlorobenzene showed its maximum at $\mathrm{RF}=200 \mathrm{~V}_{\mathrm{p}-\mathrm{p}}$.

Figure 6 shows the measured intensities of the acetaldehyde, acetone, benzene, and dichlorobenzene as function of DC field. Intensities of most of the investigated compounds showed a substantial increase when the DC field was increased from 4.5 to $13.5 \mathrm{~V} / \mathrm{cm}$; when the DC voltage was further increased up to $27 \mathrm{~V} / \mathrm{cm}$, they showed variations < $10 \%$. This was with the exception of dichlorobenzene which showed steadily increasing intensity with increasing DC voltage, with its maximum at $\mathrm{DC}=27 \mathrm{~V} / \mathrm{cm}$. 


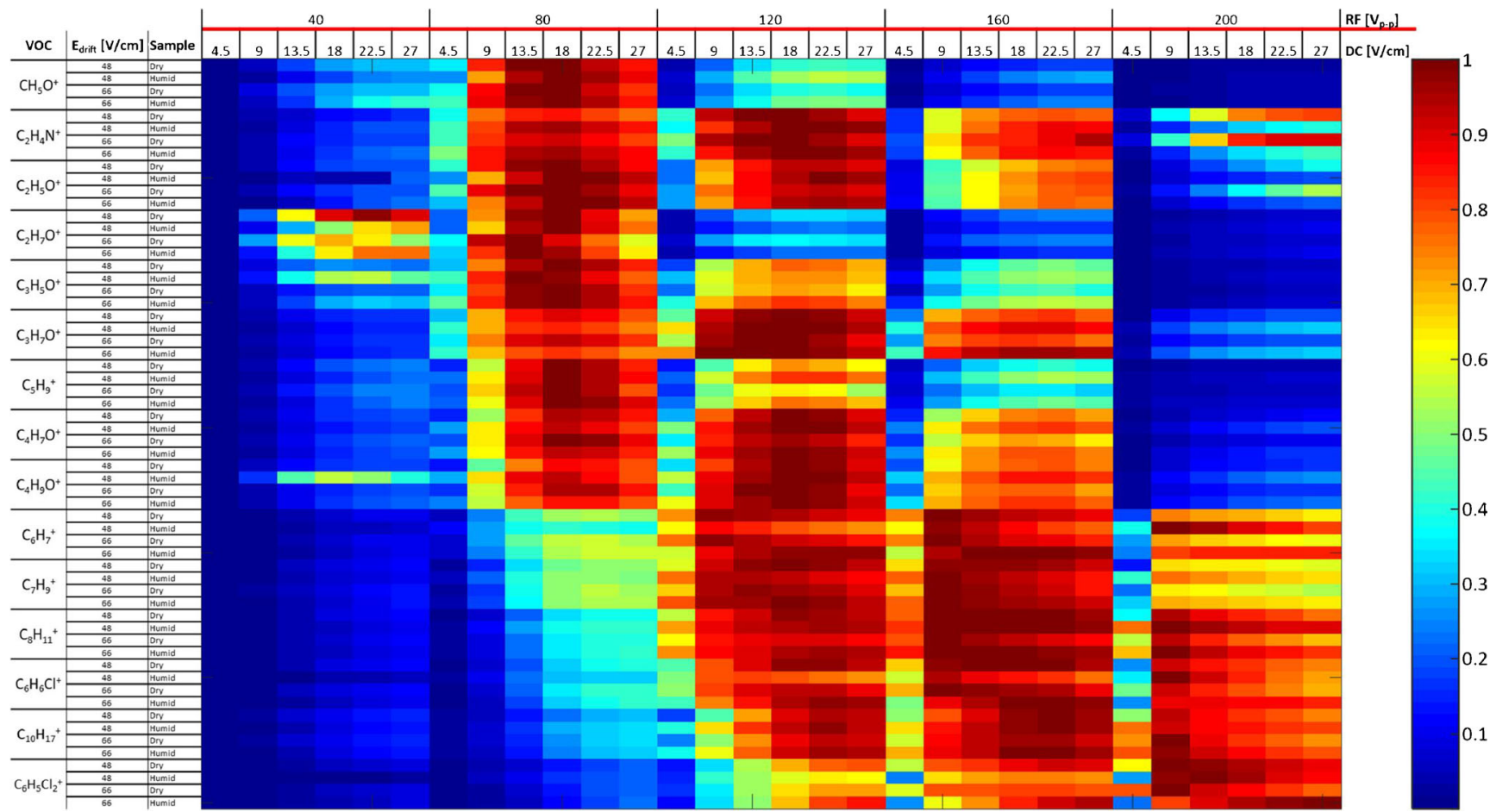

Fig. 4 Effect of RF voltage (40-200 $\left.\mathrm{V}_{\mathrm{p}-\mathrm{p}}\right)$ and DC field $(4.5-27 \mathrm{~V} / \mathrm{cm})$ on VOC intensities. The whole experiment was conducted at $E_{\text {drift }}$ of $48 \mathrm{~V} / \mathrm{cm}$ and $66 \mathrm{~V} / \mathrm{cm}$, with dry and humid samples (humidity of $47 \mathrm{~g} \mathrm{~m}^{-3}$ ). Data were normalized to maximum values to emphasize relative changes

Table 1 compares sensitivities and limits of detection (LODs) calculated for DC-mode and RF-mode for all the investigated VOCs. Sensitivity is expressed as ion count rate per second per part-per-billion volume mixing ratio of supplied analyte (cps/ppbV). LODs were calculated for $1 \mathrm{~s}$ of integration time using the " $3 \sigma$ method" with $\sigma$ being the standard deviation of the background noise level [18]. The DC-mode data were collected at $E_{\text {drift }}=66 \mathrm{~V} / \mathrm{cm}, \mathrm{RF}=0 \mathrm{~V}_{\mathrm{p}-\mathrm{p}}$, and $\mathrm{DC}=66 \mathrm{~V} / \mathrm{cm}$

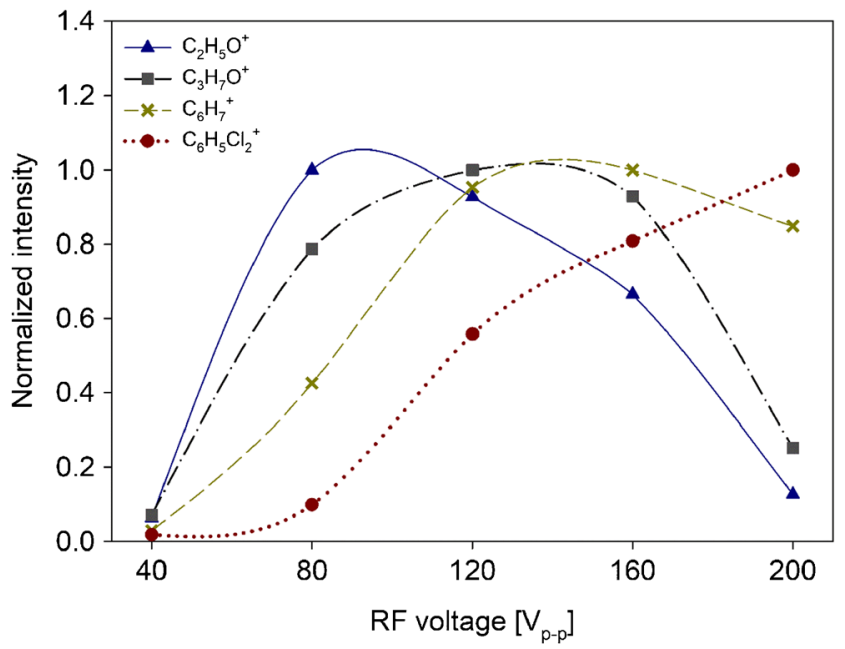

Fig. 5 Intensities of acetaldehyde (blue triangle), acetone (grey square), benzene (yellow cross), and dichlorobenzene (red round) as function of $\mathrm{RF}$ voltage. DC field was $13.5 \mathrm{~V} / \mathrm{cm}$ and $E_{\text {drift }}$ was $66 \mathrm{~V} / \mathrm{cm}$. Data were normalized onto respective maximum values to emphasize the relative changes under humid conditions. The RF-mode data were collected at $E_{\text {drift }}=66 \mathrm{~V} / \mathrm{cm}, \mathrm{RF}=120 \mathrm{~V}_{\mathrm{p}-\mathrm{p}}$, and $\mathrm{DC}=13.5 \mathrm{~V} / \mathrm{cm}$ under humid conditions. At these conditions, switching from DCmode to RF-mode led to an improvement in sensitivity of about 1 order of magnitude for most of the investigated compounds with the exception of methanol, ethanol, and dichlorobenzene. In contrast, only an improvement by a factor of 2-4 was observed for the LODs in RF-mode compared with DC-mode.

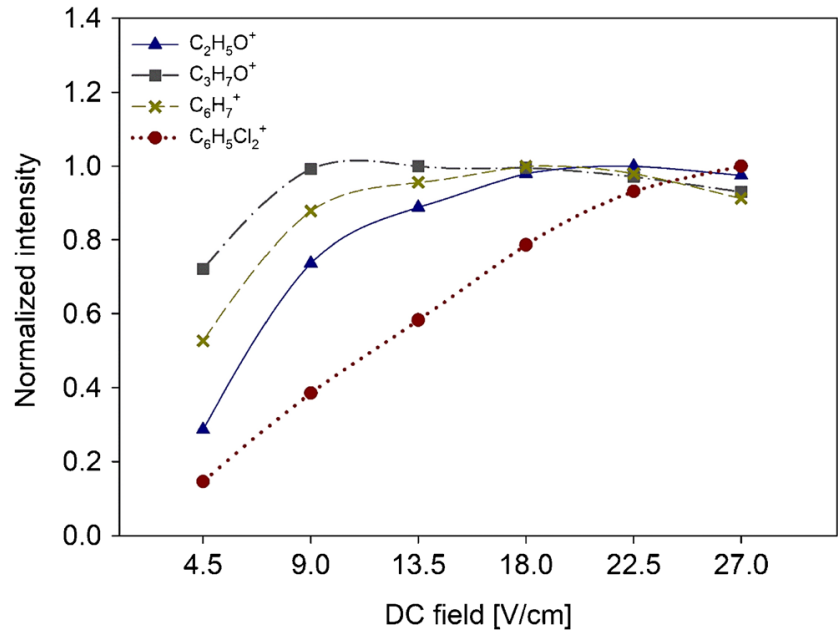

Fig. 6 Intensities of acetaldehyde (blue triangle), acetone (grey square), benzene (yellow cross), and dichlorobenzene (red round) as function of DC voltage. RF voltage was $120 \mathrm{~V}_{\mathrm{p}-\mathrm{p}}$ and $E_{\text {drift }}$ was $66 \mathrm{~V} / \mathrm{cm}$. Data were normalized onto respective maximum values to emphasize the relative changes 
Table 1 Comparison of sensitivities and LODs for DCmode and RF-mode of all investigated VOCs. LODs were calculated for $1 \mathrm{~s}$ of integration time. The DC-mode data were collected at $E_{\text {drift }}=66 \mathrm{~V} / \mathrm{cm}$, $\mathrm{RF}=0 \mathrm{~V}_{\mathrm{p}-\mathrm{p}}$, and $\mathrm{DC}=66 \mathrm{~V} / \mathrm{cm}$ under humid conditions. The RFmode data were collected at $E_{\text {drift }}=66 \mathrm{~V} / \mathrm{cm}, \mathrm{RF}=120 \mathrm{~V}_{\mathrm{p}-\mathrm{p}}$, and $\mathrm{DC}=13.5 \mathrm{~V} / \mathrm{cm}$ under humid conditions

\begin{tabular}{|c|c|c|c|c|c|c|}
\hline \multirow[b]{2}{*}{ Compound $(m / z)$} & \multicolumn{2}{|c|}{ 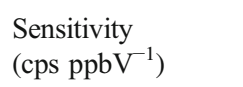 } & \multirow[b]{2}{*}{$\begin{array}{l}\text { RF-mode/DC- } \\
\text { mode }\end{array}$} & \multicolumn{2}{|c|}{ LOD (ppbV) } & \multirow[b]{2}{*}{$\begin{array}{l}\text { RF-mode/DC- } \\
\text { mode }\end{array}$} \\
\hline & $\begin{array}{l}\text { DC- } \\
\text { mode }\end{array}$ & $\begin{array}{l}\text { RF- } \\
\text { mode }\end{array}$ & & $\begin{array}{l}\text { DC- } \\
\text { mode }\end{array}$ & $\begin{array}{l}\text { RF- } \\
\text { mode }\end{array}$ & \\
\hline Methanol (33) & 27.5 & 116.5 & 4.2 & 0.735 & 0.432 & 1.7 \\
\hline Acetonitrile (42) & 46.7 & 418.2 & 8.6 & 0.337 & 0.11 & 3.1 \\
\hline Acetaldehyde (45) & 56.5 & 458.1 & 8.1 & 0.66 & 0.245 & 2.7 \\
\hline Ethanol (47) & 3.4 & 18.2 & 5.3 & 12.319 & 8.31 & 1.5 \\
\hline 2-Propenal (57) & 43 & 406.3 & 9.4 & 0.301 & 0.146 & 2.1 \\
\hline Acetone (59) & 103.6 & 1008.3 & 9.7 & 0.26 & 0.09 & 2.9 \\
\hline Isoprene (69) & 10 & 120.8 & 12.1 & 1.226 & 0.463 & 2.6 \\
\hline 2-Butenal (71) & 65.8 & 701 & 10.7 & 0.163 & 0.069 & 2.4 \\
\hline 2-Butanone (73) & 66.1 & 750.9 & 11.4 & 0.325 & 0.104 & 3.1 \\
\hline Benzene (79) & 39.2 & 423.6 & 10.8 & 0.22 & 0.056 & 3.9 \\
\hline Toluene (93) & 50.2 & 620.3 & 12.4 & 0.144 & 0.06 & 2.4 \\
\hline$o$-Xylene (107) & 65.4 & 747.4 & 11.4 & 0.115 & 0.03 & 3.8 \\
\hline Chlorobenzene (113) & 38.2 & 413.7 & 10.8 & 0.155 & 0.061 & 2.5 \\
\hline$\alpha$-Pinene (137) & 25.7 & 252.1 & 9.8 & 0.265 & 0.087 & 3 \\
\hline $\begin{array}{l}\text { 1,2-Dichlorobenzene } \\
\text { (147) }\end{array}$ & 43.9 & 264.7 & 6.0 & 0.087 & 0.044 & 2 \\
\hline
\end{tabular}

\section{Application in human breath samples}

In a proof-of-concept study, the instrument operating both in DC-mode and RF-mode was applied for breath analysis of 21 human healthy subjects.

Table 2 contains the list of VOCs that could be detected in exhaled breath. Compounds that could only be detected in RFmode are labelled using bold italic text. Concentrations of these compounds were below the LODs in DC-mode and above the LODs in RF-mode.

Concentrations and LODs and LOQs were calculated applying the kinetic theory $[19,20]$.

\section{Discussion}

Incorporation of a modular IF adjacent to the DT led to a substantial improvement in sensitivity and LODs of the PTR-ToF-MS instrument. Improved sensitivities allowed the detection of a broader range of VOCs from human breath samples in real-time.

Intensities determined for water reagent ions $\left(\mathrm{H}_{3} \mathrm{O}^{+}\right.$. $\left(\mathrm{H}_{2} \mathrm{O}\right)_{n}, n=0,1$, and 2) and for protonated VOCs showed a considerable dependence on RF voltage and DC field applied to the IF region. Highest intensities for $\mathrm{H}_{3} \mathrm{O}^{+}$were observed in the $\mathrm{RF}$ range $80-120 \mathrm{~V}_{\mathrm{p}-\mathrm{p}}$ and at $\mathrm{DC}=27 \mathrm{~V} / \mathrm{cm}$. At lower and higher RF voltages, the focusing effect of the funnel was lost and ion transfer was less efficient. High RF voltages increase the kinetic energy of molecules. As binding forces in the water clusters are weak when compared with normal chemical bonding, this will lead to collisional decomposition of water clusters long before fragmentation of chemical compounds occurs. Higher $\mathrm{H}_{3} \mathrm{O}^{+}$intensities in humid samples were most probably due to back diffusion of sample gas from the DT into the ion source generating additional $\mathrm{H}_{3} \mathrm{O}^{+}[15,21,22]$. $\mathrm{O}_{2}{ }^{+}$and $\mathrm{NO}^{+}$were present in low intensities and were observed in RF-mode only at high RF voltage $\left(>160 \mathrm{~V}_{\mathrm{p}-\mathrm{p}}\right)$ as a result of improved ion transmission [13, 23].

VOCs showed maximum intensities at substance-specific DC field and RF voltage. In agreement with IF theory, cut-off values occurred at low $(<50 \mathrm{Vp}-\mathrm{p}) \mathrm{RF}$ voltages for all VOCs and at high (>160 Vp-p) RF voltages for low-mass compounds $(m / z<90)$. At low RF voltages, the focusing effect of IF is lost for low and high masses. In a substance-specific way, higher masses show maximum transmission at high (> $120 \mathrm{Vp}-\mathrm{p}) \mathrm{RF}$ voltages due to the dependency of effective potential onto $\mathrm{m} / \mathrm{z}$. Decreasing transmission of low masses at high RF voltages is attributed to diffusional loss of molecules due to the relatively high kinetic energy of low-mass molecules under these conditions $[12,24]$. In addition, fragmentation may contribute to this effect, as we observed a $10 \%$ increase in acetaldehyde fragmentation with increasing RF voltage. Up to $50 \%$ fragmentation was reported by Barber et al. under similar conditions.

In contrast to oxygen-containing aliphatic substances, aromatic compounds showed increasing ion yields of the protonated monomers even at high RF voltages where non-aromatic substances already exhibited decreasing intensities. Enhanced 
Table 2 List of VOCs that could be detected from exhaled breath in real-time. Compounds that could only be detected in RF-mode compared with DC-mode are labelled using bold italic text. The DC-mode data were collected at $E_{\text {drift }}=66 \mathrm{~V} / \mathrm{cm}, \mathrm{RF}=0 \mathrm{~V}$ p-p , and $\mathrm{DC}=66 \mathrm{~V} / \mathrm{cm}$. The RFmode data were collected at $E_{\text {drift }}=66 \mathrm{~V} / \mathrm{cm}, \mathrm{RF}=120 \mathrm{~V}$ p-p , and DC $=$ $13.5 \mathrm{~V} / \mathrm{cm}$

\begin{tabular}{|c|c|c|c|c|c|c|c|c|c|c|}
\hline $\begin{array}{l}\text { Peak } \\
\text { number }\end{array}$ & $\begin{array}{l}\text { Measured } \\
\text { mass }(m / z)\end{array}$ & $\begin{array}{l}\text { Exact } \\
\text { mass } \\
(m / z)\end{array}$ & $\begin{array}{l}\text { Mass } \\
\text { accuracy } \\
(\mathrm{ppm})\end{array}$ & $\begin{array}{l}\text { Empirical } \\
\text { formula }\end{array}$ & $\begin{array}{l}\text { Concentration } \\
\text { range (ppbV) }\end{array}$ & $\begin{array}{l}\text { LOD DC- } \\
\text { mode } \\
(\mathrm{ppbV})\end{array}$ & $\begin{array}{l}\text { LOD RF- } \\
\text { mode } \\
(\mathrm{ppbV})\end{array}$ & $\begin{array}{l}\text { LOQ DC- } \\
\text { mode } \\
(\mathrm{ppbV})\end{array}$ & $\begin{array}{l}\text { LOQ RF- } \\
\text { mode } \\
(\mathrm{ppbV})\end{array}$ & $\begin{array}{l}\text { Potential } \\
\text { compound }\end{array}$ \\
\hline 1 & 33.031 & 33.033 & -60.55 & $\mathrm{CH}_{4} \mathrm{O}^{+}$ & $37.401-364.033$ & 0.735 & 0.432 & 2.426 & 1.426 & Methanol \\
\hline 2 & 42.031 & 42.034 & -71.37 & $\mathrm{C}_{2} \mathrm{H}_{4} \mathrm{~N}^{+}$ & $2.443-76.18$ & 0.337 & 0.11 & 1.112 & 0.363 & Acetonitrile \\
\hline 3 & 47.046 & 47.049 & -63.76 & $\mathrm{C}_{2} \mathrm{H}_{6} \mathrm{O}^{+}$ & $12.332-74.094$ & 12.319 & 8.31 & 40.653 & 27.423 & Ethanol \\
\hline 4 & 59.053 & 59.049 & 67.74 & $\mathrm{C}_{3} \mathrm{H}_{7} \mathrm{O}^{+}$ & $133.39-1043.864$ & 0.26 & 0.09 & 0.858 & 0.297 & Acetone \\
\hline 5 & 61.031 & 61.028 & 49.16 & $\mathrm{C}_{2} \mathrm{H}_{5} \mathrm{O}_{2}^{+}$ & $4.328-40.298$ & 0.865 & 0.763 & 2.855 & 2.518 & Acetic acid \\
\hline 6 & 63.028 & 63.026 & 31.73 & $\mathrm{C}_{2} \mathrm{H}_{7} \mathrm{~S}^{+}$ & $1.435-10.894$ & 0.203 & 0.12 & 0.67 & 0.396 & Dimethylsulfide \\
\hline 7 & 69.072 & 69.070 & 28.96 & $\mathrm{C}_{5} \mathrm{H}_{9}^{+}$ & $31.166-193.766$ & 1.226 & 0.463 & 4.046 & 1.528 & Isoprene \\
\hline 8 & 71.052 & 71.049 & 42.22 & $\mathrm{C}_{4} \mathrm{H}_{7} \mathrm{O}^{+}$ & $0.25-6.957$ & 0.163 & 0.069 & 0.538 & 0.228 & 2-Butenal \\
\hline 9 & 73.069 & 73.065 & 54.75 & $\mathrm{C}_{4} \mathrm{H}_{9} \mathrm{O}^{+}$ & $1.26-3.769$ & 0.325 & 0.104 & 1.073 & 0.343 & Butanone \\
\hline 10 & 79.052 & 79.054 & -25.30 & $\mathrm{C}_{6} \mathrm{H}_{7}^{+}$ & $0.309-8.362$ & 0.22 & 0.056 & 0.726 & 0.185 & Benzene \\
\hline 11 & 87.073 & 87.080 & -80.39 & $\mathrm{C}_{5} \mathrm{H}_{11} \mathrm{O}^{+}$ & $0.62-1.643$ & 0.349 & 0.272 & 1.152 & 0.898 & Pentanal \\
\hline 12 & 89.052 & 89.060 & -89.83 & $\mathrm{C}_{4} \mathrm{H}_{9} \mathrm{O}_{2}^{+}$ & $0.469-5.146$ & 0.203 & 0.126 & 0.67 & 0.416 & Ethylacetate \\
\hline 13 & 93.073 & 93.070 & 32.23 & $\mathrm{C}_{7} \mathrm{H}_{9}^{+}$ & $0.413-7.61$ & 0.144 & 0.06 & 0.475 & 0.198 & Toluene \\
\hline 14 & 137.129 & 137.132 & -21.88 & $\mathrm{C}_{10} \mathrm{H}_{17}^{+}$ & $0.911-12.413$ & 0.265 & 0.087 & 0.875 & 0.287 & Limonene \\
\hline 15 & 49.008 & 49.010 & -40.81 & $\mathrm{CH}_{5} \mathrm{~S}^{+}$ & $0.194-2.452$ & 0.354 & 0.073 & 1.168 & 0.241 & Methyl mercaptan \\
\hline 16 & 68.053 & 68.049 & 58.78 & $\mathrm{C}_{4} \mathrm{H}_{6} \mathrm{~N}^{+}$ & $0.067-0.558$ & 0.141 & 0.032 & 0.465 & 0.106 & Pyrrole \\
\hline 17 & 80.047 & 80.049 & -24.98 & $C_{5} H_{6} N^{+}$ & $0.068-0.713$ & 0.215 & 0.039 & 0.71 & 0.129 & Pyridine \\
\hline 18 & 85.063 & 85.065 & -23.51 & $\mathrm{C}_{5} \mathrm{H}_{9} \mathrm{O}^{+}$ & $0.331-1.218$ & 0.323 & 0.266 & 1.066 & 0.878 & 3-Penten-2-one \\
\hline 19 & 91.055 & 91.057 & -21.96 & $C_{4} H_{11} S^{+}$ & $0.168-1.091$ & 0.263 & 0.092 & 0.868 & 0.304 & $\begin{array}{l}\text { Methyl propyl } \\
\text { sulfide }\end{array}$ \\
\hline 20 & 97.061 & 97.065 & -41.21 & $\mathrm{C}_{6} \mathrm{H}_{9} \mathrm{O}^{+}$ & $0.248-3.97$ & 0.334 & 0.13 & 1.102 & 0.429 & 2,5-Dimethylfuran \\
\hline 21 & 101.055 & 101.060 & -49.48 & $\mathrm{C}_{5} \mathrm{H}_{8} \mathrm{O}_{2}^{+}$ & $0.218-0.737$ & 0.261 & 0.195 & 0.861 & 0.644 & Coffee furanone \\
\hline 22 & 105.056 & 105.054 & 19.04 & $\mathrm{C}_{4} \mathrm{H}_{9} \mathrm{O}_{3}^{+}$ & $0.142-0.785$ & 0.242 & 0.12 & 0.799 & 0.396 & $\begin{array}{l}\beta \text {-Hydroxybutyric } \\
\text { acid }\end{array}$ \\
\hline 23 & 106.069 & 106.065 & 37.71 & $\mathrm{C}_{7} \mathrm{H}_{8} \mathrm{~N}^{+}$ & $0.017-0.094$ & 0.088 & 0.05 & 0.29 & 0.165 & Vinylpyridine \\
\hline 24 & 108.074 & 108.081 & -64.77 & $\mathrm{C}_{7} \mathrm{H}_{10} \mathrm{~N}^{+}$ & $0.063-0.242$ & 0.202 & 0.077 & 0.667 & 0.254 & o-Toluidine \\
\hline 25 & 118.065 & 118.058 & 59.29 & $C_{8} H_{8} N^{+}$ & $0.051-0.569$ & 0.084 & 0.014 & 0.277 & 0.046 & Indole \\
\hline 26 & 125.088 & 125.096 & -63.95 & $\mathrm{C}_{8} \mathrm{H}_{13} \mathrm{O}^{+}$ & $0.042-0.343$ & 0.168 & 0.089 & 0.554 & 0.294 & Acetylcyclohexene \\
\hline 27 & 129.077 & 129.070 & 54.23 & $\mathrm{C}_{10} \mathrm{H}_{9}^{+}$ & $0.07-0.153$ & 0.161 & 0.059 & 0.531 & 0.195 & Naphthalene \\
\hline 28 & 133.058 & 133.065 & -52.61 & $\mathrm{C}_{9} \mathrm{H}_{9} \mathrm{O}^{+}$ & $0.042-0.142$ & 0.12 & 0.04 & 0.396 & 0.132 & Cinnamaldehyde \\
\hline 29 & 135.088 & 135.080 & 59.22 & $\mathrm{C}_{9} \mathrm{H}_{11} \mathrm{O}^{+}$ & $0.074-0.317$ & 0.167 & 0.075 & 0.551 & 0.248 & Cinnamyl alcohol \\
\hline 30 & 149.055 & 149.060 & -33.54 & $\mathrm{C}_{9} \mathrm{H}_{9} \mathrm{O}_{2}^{+}$ & $0.095-0.561$ & 0.223 & 0.126 & 0.736 & 0.416 & Cinnamic acid \\
\hline 31 & 151.110 & 151.112 & -13.24 & $\mathrm{C}_{10} \mathrm{H}_{15} \mathrm{O}^{+}$ & $0.054-0.233$ & 0.118 & 0.049 & 0.389 & 0.162 & Carvone \\
\hline
\end{tabular}

ability of aromatic systems to stabilize ionic states may explain efficient generation of molecule ions without losses through fragmentation even at high RF voltages. This hypothesis is further confirmed by dichlorobenzene showing an almost linear increase with increasing RF voltages, most probably due to the additional charge-stabilizing effects of the chlorine atoms.

In contrast to previous setups, with the IF used in this study, sensitivity increases were rather uniform, i.e. approximately one order of magnitude for all investigated compounds. This is a strong indicator that the IF does not have major effects onto the ion chemistry within the DT itself. Therefore, the advantages of PTR-MS, e.g. quantification without calibration, are preserved. Although Brown and Barber et al. reported relative increases in sensitivity of 1-2 orders of magnitude for single compounds (acetaldehyde $45 \times$, acetone $200 \times$ ), absolute sensitivities for a broad range of compounds reported in our study were in general higher, e.g. 10 times higher for methanol and 2 times higher for acetaldehyde. Higher improvements in relative sensitivity as well as higher fragmentation rates 
reported by Barber and Brown et al. can thus be attributed to different geometries of IF and DT in their instruments.

Characterization and optimization of DT conditions, RF voltage, and DC field and effects of humidity are of general importance for any IF-PTR-ToF instrument and can therefore be beneficial for the whole community [20]. In addition, the modular IF described in this study can be implemented into several PTR-ToF-MS instruments.

The impact of the IF onto quantification can be seen when LODs and LOQs are looked upon. As the applied IF will improve transmission of the ions, in parallel to the desired effects, increased ion yields will also induce growing background noise. Thus, the "raw" gain in ion counts will not directly translate into identical improvements of LODs and LOQs. LODs and LOQs substantially depend on noise inherent in a PTR-MS signal. This noise can be described by a Poisson distribution: the $1 \sigma$ error in a measurement that is derived from counting a total of $N$ ions is $\sqrt{N \cdot \tau^{-1}}$, with $\tau$ being the integration time $[19,25,26]$. Taking this into account, LODs and LOQs could effectively be improved by a factor of 2-4 when the instrument was switched from DCmode to RF-mode. Hence, just determining increases in ion yields may lead to overestimation of the instrument performances for quantitative analysis. For real-life applications, e.g. trace gas analysis in breath, LODs and LOQs have to be determined to take into account all effects of DC field and RF voltage applied within the IF.

Especially in diseased states, breath VOC concentrations may change quickly and abruptly. Hence, only real-time monitoring can provide complete and comprehensive information from breath VOC analysis [27-29]. PTR-ToF-MS with integration time of $\geq 200 \mathrm{~ms}$ enables breath-resolved continuous monitoring of breath volatiles. In this pilot study, the range of detectable volatile substances was significantly enlarged through application of IF technology.

\section{Conclusion}

The spectrum of detectable VOCs in real-time breath analysis was considerably enhanced through the application of IF technology. The IF can be tuned in order either to obtain the best operating conditions for a specific compound of interest or to realize operating conditions which represent the best compromise for the acquisition of a large number of compounds. In contrast to previous setups, the IF used in this study did not have major effects onto ion chemistry within the DT itself and therefore offers optimal conditions for VOC screening in biomedical applications.

Acknowledgements Giovanni Pugliese acknowledges useful discussions with Professor C. A. Mayhew (Head of Molecular Physics Group at the University of Birmingham, Director of the Institute for Breath Research at the Leopold-Franzens-Universität Innsbruck, Coordinator IMPACT EU ITN) during his visit at the Rostock University Medical Center in July 2019. Finally, we thank all the volunteers and the IONICON Analytik GmbH employees for participating and supporting this study.

Funding information Open Access funding provided by Projekt DEAL. This study was financially funded by the European Union's Horizon 2020 research and innovation programme under the Marie Skłodowska-Curie grant agreement no. 674911-IMPACT. Giovanni Pugliese and Felix Piel are Early Stage Researchers within the IMPACT programme.

\section{Compliance with ethical standards}

Conflict of interest Felix Piel and Philipp Sulzer work for IONICON Analytik $\mathrm{GmbH}$, which provided the instrument used in this study. The other authors declare that they have no conflict of interest.

Research involving human participants All experiments were performed in accordance with the guidelines laid down in the Declaration of Helsinki and approved by the ethics committee at University Medical Center Rostock.

Informed consent Informed consent was obtained from all volunteers.

Open Access This article is licensed under a Creative Commons Attribution 4.0 International License, which permits use, sharing, adaptation, distribution and reproduction in any medium or format, as long as you give appropriate credit to the original author(s) and the source, provide a link to the Creative Commons licence, and indicate if changes were made. The images or other third party material in this article are included in the article's Creative Commons licence, unless indicated otherwise in a credit line to the material. If material is not included in the article's Creative Commons licence and your intended use is not permitted by statutory regulation or exceeds the permitted use, you will need to obtain permission directly from the copyright holder. To view a copy of this licence, visit http://creativecommons.org/licenses/by/4.0/.

\section{References}

1. Ellis AM, Mayhew CA. Proton transfer reaction mass spectrometry: principles and applications. John Wiley \& Sons. 2013.

2. Hansel A, Jordan A, Holzinger R, Prazeller P, Vogel W, Lindinger W. Proton-transfer reaction mass-spectrometry - online trace gasanalysis at the ppb level. Int J Mass Spectrom. 1995;149:609-19. https://doi.org/10.1016/0168-1176(95)04294-U.

3. Graus M, Müller M, Hansel A. High resolution PTR-TOF: quantification and formula confirmation of VOC in real time. J Am Soc Mass Spectrom. 2010;21:1037-44. https://doi.org/10.1016/j.jasms. 2010.02.006.

4. Blake RS, Whyte C, Hughes CO, Ellis AM, Monks PS. Demonstration of proton-transfer reaction time-of-flight mass spectrometry for real-time analysis of trace volatile organic compounds. Anal Chem. 2004;76:3841-5. https://doi.org/10.1021/ac0498260.

5. Jordan A, Haidacher S, Hanel G, Hartungen E, Märk L, Seehauser $\mathrm{H}$, et al. A high resolution and high sensitivity proton-transferreaction time-of-flight mass spectrometer (PTR-TOF-MS). Int J Mass Spectrom. 2009;286:122-8. https://doi.org/10.1016/j.ijms. 2009.07.005.

6. Müller M, Piel F, Gutmann R, Sulzer P, Hartungen E, Wisthaler A. A novel method for producing $\mathrm{NH} 4+$ reagent ions in the hollow cathode glow discharge ion source of PTR-MS instruments. Int $\mathrm{J}$ 
Mass Spectrom. 2020;447:116254. https://doi.org/10.1016/j.ijms. 2019.116254.

7. Jordan A, Haidacher S, Hanel G, Hartungen E, Herbig J, Märk L, et al. An online ultra-high sensitivity proton-transfer-reaction massspectrometer combined with switchable reagent ion capability (PTR+SRI-MS). Int J Mass Spectrom. 2009;286:32-8. https:// doi.org/10.1016/j.ijms.2009.06.006.

8. Shaffer SA, Tang K, Anderson GA, Prior DC, Udseth HR, Smith $\mathrm{RD}$. A novel ion funnel for focusing ions at elevated pressure using electrospray ionization mass spectrometry. Rapid Commun Mass Spectrom. 1997;11:1813-7. https://doi.org/10.1002/(SICI)10970231(19971030)11:16<1813::AID-RCM87>3.0.CO;2-D.

9. Barber S, Blake RS, White IR, Monks PS, Reich F, Mullock S, et al. Increased sensitivity in proton transfer reaction mass spectrometry by incorporation of a radio frequency ion funnel. Anal Chem. 2012;84:5387-91. https://doi.org/10.1021/ac300894t.

10. González-Méndez R, Watts P, Olivenza-León D, Reich DF, Mullock SJ, Corlett CA, et al. Enhancement of compound selectivity using a radio frequency ion-funnel proton transfer reaction mass spectrometer: improved specificity for explosive compounds. Anal Chem. 2016;88:10624-30. https://doi.org/10.1021/acs.analchem. 6 b02982.

11. Brown PA, Cristescu SM, Mullock SJ, Reich DF, Lamont-Smith CS, Harren FJM. Implementation and characterization of an RF ion funnel ion guide as a proton transfer reaction chamber. Int J Mass Spectrom. 2017;414:31-8. https://doi.org/10.1016/j.ijms.2017.01. 001.

12. Kelly RT, Tolmachev AV, Page JS, Tang K, Smith RD. The ion funnel: theory, implementations, and applications. Mass Spectrom Rev. 2010;29:294-312. https://doi.org/10.1002/mas.20232.

13. Blake RS, Monks PS, Ellis AM. Proton-transfer reaction mass spectrometry. Chem Rev. 2009;109:861-96. https://doi.org/10.1021/ cr800364q.

14. Breitenlechner M, Fischer L, Hainer M, Heinritzi M, Curtius J, Hansel A. PTR3: an instrument for studying the lifecycle of reactive organic carbon in the atmosphere. Anal Chem. 2017;89:5824-31. https://doi.org/10.1021/acs.analchem.6b05110.

15. Trefz P, Schubert JK, Miekisch W. Effects of humidity, CO2 and $\mathrm{O} 2$ on real-time quantitation of breath biomarkers by means of PTR-ToF-MS. J Breath Res. 2018;12:026016. https://doi.org/10. 1088/1752-7163/aa9eea.

16. de Gouw JA, Goldan PD, Warneke C, Kuster WC, Roberts JM, Marchewka M, et al. Validation of proton transfer reaction-mass spectrometry (PTR-MS) measurements of gas-phase organic compounds in the atmosphere during the New England Air Quality Study (NEAQS) in 2002. J Geophys Res Atmospheres. 2003;108. https://doi.org/10.1029/2003JD003863.

17. Trefz P, Schmidt M, Oertel P, Obermeier J, Brock B, Kamysek S, et al. Continuous real time breath gas monitoring in the clinical environment by proton-transfer-reaction-time-of-flight-mass spectrometry. Anal Chem. 2013;85:10321-9. https://doi.org/10.1021/ ac402298v.

18. Sulzer P, Hartungen E, Hanel G, Feil S, Winkler K, Mutschlechner $\mathrm{P}$, et al. A proton transfer reaction-quadrupole interface time-of- flight mass spectrometer (PTR-QiTOF): high speed due to extreme sensitivity. Int J Mass Spectrom. 2014;368:1-5. https://doi.org/10. 1016/j.ijms.2014.05.004.

19. de Gouw J, Warneke C. Measurements of volatile organic compounds in the earth's atmosphere using proton-transfer-reaction mass spectrometry. Mass Spectrom Rev. 2007;26:223-57. https:// doi.org/10.1002/mas.20119.

20. Yuan B, Koss AR, Warneke C, Coggon M, Sekimoto K, de Gouw JA. Proton-transfer-reaction mass spectrometry: applications in atmospheric sciences. Chem Rev. 2017;117:13187-229. https://doi. org/10.1021/acs.chemrev.7b00325.

21. Beauchamp J, Herbig J, Dunkl J, Singer W, Hansel A. On the performance of proton-transfer-reaction mass spectrometry for breath-relevant gas matrices. Meas Sci Technol. 2013;24:125003. https://doi.org/10.1088/0957-0233/24/12/125003.

22. Smith D, Španěl P, Herbig J, Beauchamp J. Mass spectrometry for real-time quantitative breath analysis. J Breath Res. 2014;8:027101. https://doi.org/10.1088/1752-7155/8/2/027101.

23. Trefz P, Pugliese G, Brock B, Schubert J, Miekisch W. Effects of elevated oxygen levels on VOC analysis by means of PTR-ToFMS. J Breath Res. 2019;13:046004. https://doi.org/10.1088/17527163/ab28ec .

24. Shaffer SA, Tolmachev A, Prior DC, Anderson GA, Udseth HR, Smith RD. Characterization of an improved electrodynamic ion funnel interface for electrospray ionization mass spectrometry. Anal Chem. 1999;71:2957-64. https://doi.org/10.1021/ ac990346w.

25. Warneke C, de Gouw JA, Kuster WC, Goldan PD, Fall R. Validation of atmospheric VOC measurements by protontransfer- reaction mass spectrometry using a gas-chromatographic preseparation method. Environ Sci Technol. 2003;37:2494-501. https://doi.org/10.1021/es026266i.

26. Hayward S, Hewitt CN, Sartin JH, Owen SM. Performance characteristics and applications of a proton transfer reaction-mass spectrometer for measuring volatile organic compounds in ambient air. Environ Sci Technol. 2002;36:1554-60. https://doi.org/10.1021/ es0102181.

27. Sukul P, Schubert JK, Oertel P, Kamysek S, Taunk K, Trefz P, et al. FEV manoeuvre induced changes in breath VOC compositions: an unconventional view on lung function tests. Sci Rep. 2016;6: 28029. https://doi.org/10.1038/srep28029.

28. Brock B, Kamysek S, Silz J, Trefz P, Schubert JK, Miekisch W. Monitoring of breath VOCs and electrical impedance tomography under pulmonary recruitment in mechanically ventilated patients. J Breath Res. 2017;11:016005. https://doi.org/10.1088/1752-7163/ aa53b2.

29. Pugliese G, Trefz P, Brock B, Schubert J, Miekisch W. Extending PTR based breath analysis to real-time monitoring of reactive volatile organic compounds. Analyst. 2019;144:7359. https://doi.org/ 10.1039/C9AN01478K.

Publisher's note Springer Nature remains neutral with regard to jurisdictional claims in published maps and institutional affiliations. 